\title{
Phenotypic Characteristics of Hydrocephalus in Stillborn Friesian Foals
}

Veterinary Pathology

50(6) 1037-1042

(C) The Author(s) 2013

Reprints and permission:

sagepub.com/journalsPermissions.nav DOI: I0.I I77/03009858|3488955

vet.sagepub.com

(9)

\author{
K. D. Sipma', P. Cornillie ${ }^{2}$, M. N. Saulez ${ }^{3}$, T. A. E. Stout ${ }^{3,4}$, \\ G. Voorhout ${ }^{5}$, and W. Back ${ }^{1,4}$
}

\begin{abstract}
Hydrocephalus is uncommon in horses. However, in recent years, it has become clear that the prevalence of hydrocephalus is greater in Friesian horses than in other breeds probably due to their limited gene pool. Before identification of candidate genes that predispose to the development of hydrocephalus in Friesian horses can be pursued, an in-depth, phenotypic, pathological description of the condition in Friesians would be of great benefit. Our study aimed to characterize the morphology of hydrocephalus in Friesian horses, to support further investigation of the genetic background of this condition. Four stillborn Friesian foals with hydrocephalus were examined macroscopically and microscopically and compared with 2 normal stillborn Friesian foals without hydrocephalus. In all clinical cases, tetraventricular and venous dilatations were observed, together with malformation of the petrosal bone and, as a result, narrowing of the jugular foramen. These observations suggest a communicative hydrocephalus with a diminished absorption of cerebrospinal fluid into the systemic circulation at the venous sinuses due to a distorted, nonfunctional jugular foramen. This type of hydrocephalus is also recognized in humans and dogs and has been linked genetically to chondrodysplasia; this has already been recognized in dwarfism, which is another monogenetic defect in Friesian horses.
\end{abstract}

\section{Keywords}

horse, hydrocephalus, jugular foramen, phenotype, stillbirth

Congenital hydrocephalus is a common disorder in several animal species, including mice, rats, and dogs. ${ }^{8,18,21,34}$ This disorder is also encountered quite frequently in humans, with an estimated prevalence of 0.5 to 0.8 affected children per 1000 births. ${ }^{14}$ Documentation of hydrocephalus in horses is limited to a few case reports, from which one may conclude that it is uncommon in this species. ${ }^{3,5,7,15,19,24,29}$ However, in a study on the causes of abortion and stillbirth in 1985, Crowe and Swerczek ${ }^{11}$ found that hydrocephalus had a prevalence of $3 \%$ (18 of 602 cases) in thoroughbreds. The overall prevalence of abortion in horses is estimated at $2 \%$, so the prevalence of hydrocephalus can be estimated to be approximately 0.6 affected foals per 1000 births, which is similar to the prevalence in humans. ${ }^{31}$ In the past 20 to 30 years, there have been reports of a higher prevalence of hydrocephalus in Friesian horses than in other breeds or in the horse population in general. ${ }^{4}$ Due to a limited genetic pool, the Friesian breed is highly susceptible to inbreeding, with an average coefficient of approximately $15 \%{ }^{37}$

In humans, only $40 \%$ of cases of hydrocephalus are suspected to have a genetic origin, according to the Online Mendelian Inheritance in Man (OMIM). Currently, that database recognizes 269 different types of hydrocephalus. In $5 \%$ to $15 \%$ of human cases of hydrocephalus, the suspected mutation is a neuronal adhesion molecule situated on the $\mathrm{X}$ chromosome, with a recessive mode of transmission. ${ }^{16,18,35}$ Ojala and
Ala-Huikku ${ }^{27}$ have suggested that hydrocephalus in horses is hereditary, even though they could neither confirm the mode of transmission within their series nor suggest a causative gene.

Hydrocephalus is defined as a distension of the ventricular system of the brain, including or not including the arachnoid space around the brain, caused by obstruction of the normal flow of cerebrospinal fluid (CSF), increased production of CSF within the choroid plexus, or altered absorption of CSF at the arachnoid villi in the venous sinuses. ${ }^{20,30}$ Using the origin of the anomaly as a basis for analysis, different types of hydrocephalus have been identified. Obstruction usually leads to

\footnotetext{
'Department of Surgery and Anaesthesiology of Domestic Animals, Faculty of Veterinary Medicine, Ghent University, Merelbeke, Belgium

${ }^{2}$ Department of Morphology, Faculty of Veterinary Medicine, Ghent University, Merelbeke, Belgium

${ }^{3}$ Departments of Companion Animal Clinical Studies and Production Animal Sciences, Faculty of Veterinary Science, Onderstepoort, South Africa

${ }^{4}$ Department of Equine Sciences, Faculty of Veterinary Medicine, Utrecht University, Utrecht, the Netherlands

${ }^{5}$ Division of Diagnostic Imaging, Faculty of Veterinary Medicine, Utrecht University, Utrecht, the Netherlands
}

\section{Corresponding Author:}

W. Back, Department of Equine Sciences, Faculty of Veterinary Medicine, Utrecht University, Yalelaan I I 2- I 4, NL-3584 CM Utrecht, the Netherlands. Email:W.Back@uu.nl 
Table I. Case Overview and Applied Methods.

\begin{tabular}{lclll}
\hline Foal & Sex & Phenotype & Preservation & Methods \\
\hline 1 & 9 & Hydrocephalus & $4 \%$ formaldehyde perfusion & PM, CT, 3DR, H \\
2 & 9 & Hydrocephalus & None & PM \\
3 & + & Hydrocephalus & Frozen & CT, 3DR \\
4 & 0 & Hydrocephalus & $4 \%$ formaldehyde perfusion & PM, CT, 3DR, L, H, SB \\
5 & 9 & Normal & None & CT, 3DR \\
6 & 0 & Normal & None & CT, 3DR \\
\hline
\end{tabular}

Abbreviations: $\mathrm{CT}$, computed tomography; $\mathrm{H}$, histology; L, latex perfusion; PM, gross postmortem examination; SB, skull base examination; 3DR, 3-dimensional reconstructions.

internal hydrocephalus with dilatation of the ventricles rostral to the obstruction but with normal caudal ventricles. In contrast, increased production or altered absorption generally leads to an external or a communicating hydrocephalus. The most common cause of hydrocephalus in animals as a developmental disease is obstruction at the level of the aqueduct of Sylvius, the foramen of Monro, or the foramina of Luschka, even though physical obstruction is not always observed. ${ }^{22,36}$

The purpose of the study reported herein was to characterize the morphology of abnormalities that underlie hydrocephalus in Friesian horses, with the aim of supporting subsequent studies into the genetic causes of the defect in this breed.

\section{Case Histories}

Four stillborn Friesian foals with hydrocephalus (9-11 months' gestation; 2 natural parturition, 1 assisted delivery, and 1 caesarean section) were compared with 2 normal stillborn Friesian foals that died of other causes (Table 1). These 4 hydrocephalic foals were part of a total group of 22 cases collected between 2001 and 2010, as a joint effort between the official studbook (The Koninklijke Vereniging "Het Friesch Paarden-Stamboek" KFPS) and a university (Utrecht). This would mean more than 2 cases per year, which is lower than the estimated prevalence in practice (2.5:1000; $n=5000$ registered foals). ${ }^{4}$

Case Nos. 1 and 2 were recognized as congenital hydrocephalus at the Onderstepoort Veterinary Academic Hospital, Pretoria, South Africa; postmortem (PM) examination was subsequently performed. Case Nos. 3, 5, and 6 were submitted via the Faculty of Veterinary Medicine at Utrecht University, Utrecht, the Netherlands, whereas the PM on case No. 4 was performed at the Faculty of Veterinary Medicine of Ghent University, Merelbeke, Belgium.

Computed tomography (CT) of the cranium was performed on 3 hydrocephalic and 2 normal foals at the clinic of admittance using a single-slice helical scanner with a maximum slice thickness of $5 \mathrm{~mm}$ (Table 1), including 3-dimensional reconstruction analysis. ${ }^{10}$ Case Nos. 1 and 4 were also freshly fixed in $4 \%$ formaldehyde by direct perfusion through the carotid arteries. Subsequently, for case No. 4 , the blood vessels were filled with fluid latex by perfusion through the carotid artery.

Histological examination was performed on brain tissue from case Nos. 1 and 4. Tissue samples were stored in sealed leak-proof containers at $4^{\circ} \mathrm{C}$, and tissues were fixed in $10 \%$ buffered formalin for at least 72 hours. Formalin-fixed samples were routinely processed. Sections were stained with hematoxylin and eosin (HE), then further processed using standard laboratory techniques, as described previously. ${ }^{9}$ Each section was observed using a standard light microscope.

After the soft tissues had been removed, the skull of case No. 4 was placed in $\mathrm{NaOCl}$ to allow further examination of the skull base.

\section{Macroscopic Examination}

Macroscopic examination of the foals revealed extensive cranial distension (Fig. 1) with incomplete ossification, accompanied by enlargement of the temporal, frontal, and parietal bones (Fig. 2, 3) and malformation of the petrosal bone. Large thrombi had formed in the dura mater on the enlarged bones. The height from the skull base to the apex was, on average, $15.1 \mathrm{~cm}$ in affected foals (case Nos. 3 and 4), compared with $7.0 \mathrm{~cm}$ in the normal animals (case Nos. 5 and 6). The diameter of the head from left to right in hydrocephalic foals was nearly 3 times $(21.0 \mathrm{~cm})$ that in the normal foals $(8.5 \mathrm{~cm})$. In affected foals, the cranial fontanels were roughly circular; however, the effective openings to these fontanels were restricted by thin membranes of connective tissue. All ventricular cavities were extremely dilated (Fig. 4); as a result, the cerebral cortices were reduced to thin shells of nervous tissue with a thickness of $<5 \mathrm{~mm}$. This is in contrast to a normal thickness of the cerebral cortex of at least $5 \mathrm{~cm}$ in a neonatal foal. The cerebellum in affected animals was compressed and displaced caudally but did not protrude through or cause an obstruction of the foramen magnum. The hippocampus and corpus callosum were smaller than in normal animals. The caudal colliculi were absent or fused, and the rostral colliculi were partially fused. In addition, case No. 4 showed severe hydromyelia (Fig. 5). An attempt to follow a latex-perfused jugular vein into the jugular foramen was unsuccessful, but an internal approach after the brain had been removed revealed pooling of latex at the exact location where the jugular foramen would be expected, and the foramen was narrower than the foramina in the normal foals. The narrowing was explored further after all soft tissues had been removed. It was concluded that the phenomenon resulted from the absence of the caudal part of the foramen lacerum, that is, the jugular foramen or jugular notch. 


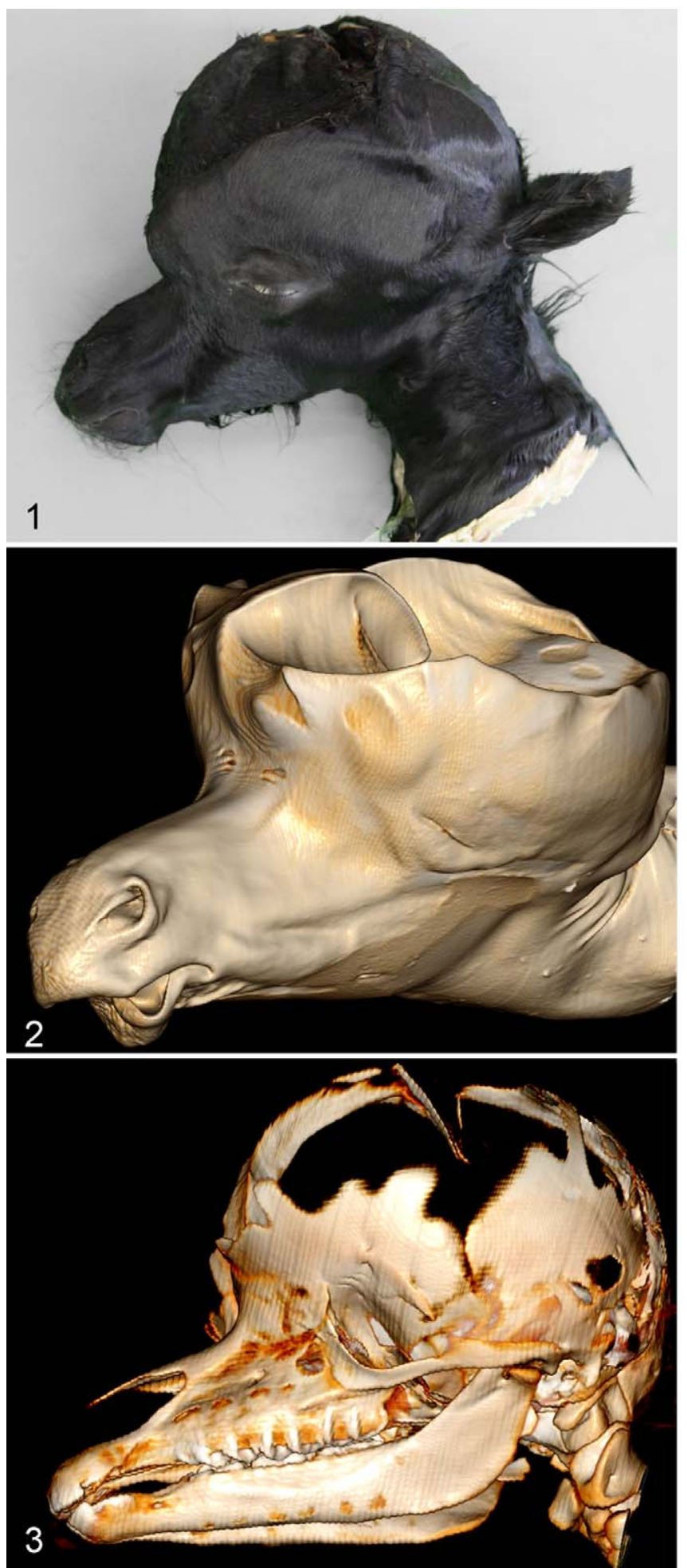

Figure I. Skull; stillborn Friesian foal, case No. 4. Left lateral view, typical example of hydrocephalus. Figure 2. Computed tomographic left lateral view of the skull of a Friesian foal, case No. 3. The 3-dimensional reconstruction image illustrates the clinical diagnosis of hydrocephalus. Figure 3. Computed tomographic left lateral view of the skull of a Friesian foal, case No. 3. The 3-dimensional reconstruction image shows that the ossification at the rostral part of the cranium is incomplete in hydrocephalus.

\section{Microscopic Examination}

Microscopic examination of the cerebral cortices showed in the affected foals a clear reduction in white and gray matter, effacing of the characteristic gyri and sulci pattern, and an average ratio of white to gray matter of 0.36 , compared with 0.50 in the normal foals (Fig. 6). Only the external granule cell layer, typical for a fetus, could still be recognized as a separate layer in the cerebellum. ${ }^{25}$ Blood vessels in all cross-sectional slices were prominent because of distension by erythrocytes (Fig. 7). Cross-sectional images of the aqueductus mesencephali showed dilatation of the canal, although the ependyma was mostly intact. The foramina of Luschka and arachnoid villi could not be identified, and inflammatory cells were absent in all cases.

\section{Computed Tomography}

There was marked doming of the cranium in Figs. 2 and 3. The cranial fontanels were clearly visible as rostral defects in the cranium of up to $7.3 \mathrm{~cm}$. The lateral ventricles were dilated to an average height of $13.4 \mathrm{~cm}$ and a width of $9.5 \mathrm{~cm}$, in contrast to an average height and width of $2.5 \mathrm{~cm}$ in normal foals. The cranial fossa was filled with homogeneous material with an average density of 13 Hounsfield units (HU), corresponding with the CSF. Along the ventral aspect of the cranium in the region of the middle cranial fossa, there was a bilateral poorly marginated area of homogeneous hypodense material with slightly higher HU than the material that occupied the rest of the cranial vault. Three-dimensional reconstructions showed a bony zone surrounding the petrosal bone on the lateral and axial sides that was larger than that found in normal foals. On average, the petrosal bone in hydrocephalic foals had a rectangular shape in cross section and was visible on 30 consecutive CT slices, which is equivalent to an average length of $6.0 \mathrm{~cm}$. In normal foals, the petrosal bone had a cuboid shape and was visible in only 21 CT slices, which corresponded to an average length of $4.2 \mathrm{~cm}$. The midline aspect of the malformed petrosal bone contributed to the outline of the jugular foramen in all cases. Three-dimensional reconstructions showed that the shapes of the foramen lacerum, petro-occipital fissure, and jugular foramen in normal foals differed bilaterally from those in hydrocephalic foals. In normal foals, this complex of foramina already had the shape typical of adult horses, and the most caudal part of this complex was at the same level as the foramen, where the hypoglossal nerve exits the cranial cavity. The rostral portion was divided into an oval and carotid notch, whereas the caudal part, the petro-occipital fissure, narrowed to connect with the cordate jugular foramen. ${ }^{6}$ In hydrocephalic foals, the complex appeared to be more rounded and the caudal cordate part appeared to be absent in the 3-dimensional reconstructions. This finding was confirmed by the observation that the most caudal part of the complex of foramina was approximately $1 \mathrm{~cm}$ more rostral than in the control animals (Figs. 8, 9). 

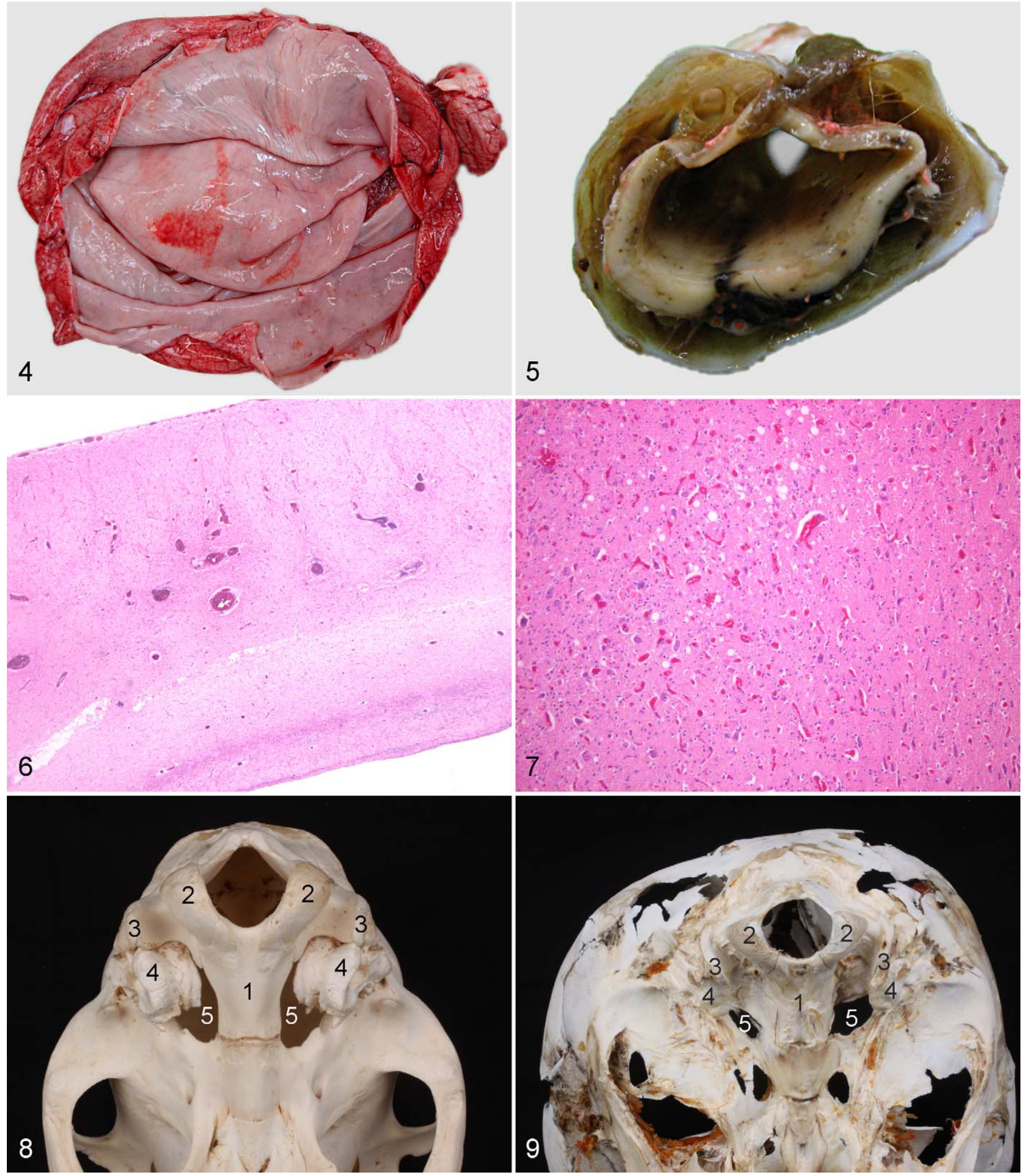

Figure 4. Cerebral hemispheres of a Friesian foal, case No. I, dorsal view. The lateral ventricles were markedly distended, and their linings are shown here, along with extremely thin cerebral cortices resulting from the increased cerebrospinal fluid (CSF) pressure in hydrocephalus. Figure 5. Spinal cord; Friesian foal, case No. I. A cross-sectional image shows obvious hydromyelia. Figure 6. Cerebrum; Friesian foal, case No. I. A cross-sectional image taken at the cerebral cortex shows the difference between white and gray matter with a reduction in mainly the white matter and the numerous dilated vessels filled with erythrocytes; obviously, the ventricle is dilated in hydrocephalus. Hematoxylin and eosin (HE). Figure 7. Cerebrum; Friesian foal, case No. I. A cross-sectional image taken at the cerebral cortex is a detailed view of Fig. 5 and 


\section{Discussion}

When evaluating hydrocephalus in any species, it is important to differentiate between developmental and inflammatory origins. Reports of inflammatory hydrocephalus in horses have not been found in the literature; in this study, we focused on developmental disorders, and inflammation was not noted in the cases described in this study. Based on the postmortem CT findings and macroscopic and microscopic examination of these 4 cases, hydrocephalus in Friesian horses appears to be either the internal or communicative type, with the majority of CSF in the internal compartment. Dilatation of all 4 ventricles, as observed in all affected animals, can occur in both the internal (noncommunicating) or the communicative types of hydrocephalus. ${ }^{1,12}$ The decreased ratio of white to gray matter suggests a thinning of primarily the white matter and confirms a major internal component. ${ }^{13}$ A physical obstruction of CSF flow could not be identified in any of our cases. However, this does not completely rule out the possibility of an obstructive internal hydrocephalus, because obvious obstruction cannot always be found in affected animals. ${ }^{22}$

Difficulties with passing latex through the vascular system may have been caused by an elevated rigidity of the blood vessels due to formaldehyde perfusion or by physical obstruction of the blood flow within the cranial vascular system. Macroscopic PM examination showed that even the smallest visible vessels were filled with latex, so the difficulties were most likely caused by physical obstruction of blood flow. Pooling of the latex at the level of the jugular foramen was again highly suggestive of vascular obstruction at that specific site.

Dilatation of the blood vessels in all histological slices may indicate an elevated venous pressure in the venous sinuses of the subarachnoid space. Resorption of CSF is a passive process driven by a pressure and concentration gradient, so elevated pressure might interfere with resorption of CSF into the systemic circulation. ${ }^{32}$ Any cause of obstruction to the venous return to the heart may result in such elevated venous pressure.

We observed partial stenosis of the jugular foramen at the base of the skull. The caudal cerebral efferent veins run through this foramen, which connects the venous petrosal sinuses and the jugular veins. ${ }^{23}$ Stenosis of the foramen is recognized in humans and $\operatorname{dogs} s^{17,34}$ as a cause of venous compression. Such compression of the jugular veins has been visualized in humans with hydrocephalus accompanied by stenosis of the jugular foramen, using magnetic resonance venography and radioactive venography with a gamma camera. ${ }^{26,39}$ Compression of the jugular veins can lead to increased cerebral venous pressure. However, it is a matter of debate whether the intracranial venous sinus hypertension is a cause or a consequence of hydrocephalus. In this context, in 1984, Sainte-Rose et $\mathrm{al}^{33}$ performed a study of hydrocephalus associated with stenosis of the jugular foramen in babies and showed that venous hypertension is most likely a cause, rather than a consequence, of hydrocephalus. In addition, Moritani et $\mathrm{al}^{26}$ in 2006 found that the degree of venous narrowing was correlated with ventricular size in such patients. This type of hydrocephalus is related to chondrodysplasia in babies, and the most common underlying cause is a mutation in one of the genes encoding several of the fibroblast growth factor receptors (FGFRs). ${ }^{39}$ Mutations in the FGFR genes have also been reported to be associated with other craniosynostosis syndromes with overlapping phenotypes. ${ }^{38}$ These mutations inhibit endochondral bone formation (chondrodysplasia) and can result in a small skull base and stenosis of the jugular foramen. ${ }^{40}$ Chondrodysplasia has also been described in dwarfism, another hereditary defect in Friesian horses, although the precise genetic origin of this condition, presumably one causal genetic defect, has not yet been identified. ${ }^{2,28}$

In conclusion, the most likely cause of hydrocephalus in Friesian horses is stenosis of the jugular foramen. As in dwarfism, this may be due to a genetic mutation with an autosomal recessive mode of transmission., ${ }^{2,4,28}$ A similar pathogenesis has been shown in a dog population with a similar, narrow genetic pool. ${ }^{34}$ Once the causative genetic defect has been identified, DNA screening potentially can be performed to identify carriers of the mutation within the Friesian horse population. Then, advice can be given to the owner to either enter a breeding program or to exclude the horse from breeding. These measures can prevent this genetic defect from spreading further within the Friesian population.

\section{Declaration of Conflicting Interests}

The author(s) declared no potential conflicts of interest with respect to the research, authorship, and/or publication of this article.

\section{Funding}

The author(s) received no financial support for the research, authorship, and/or publication of this article.

\section{References}

1. Aesch B, Goldenberg N, Maheut-Lourmiere J, et al. Hydrocephalus caused by obstruction of the foramina of Luschka and Magendie in adults: report of a case. Etiopathogenic discussion. Neurochirurgie. 1991;37:269-272.

Figure 7. (continued). shows the vacuolar appearance of the brain tissue and the numerous dilated vessels filled with erythrocytes in hydrocephalus. HE. Figure 8. Detailed ventral view of the skull base of a normal neonatal foal from the regular university anatomical collection with the nose pointing downward. The image shows extension of the foramen lacerum medial and caudomedial to the petrosal bone, as well as at the (I) basilar part of the occipital bone, (2) occipital condyles flanking the foramen magnum, (3) paracondylar process, (4) petrosal bone, and (5) foramen lacerum. Figure 9. Detailed ventral view of the skull base of a Friesian foal with the nose pointing downward, case No. 4. The image shows hydrocephalus with absence of the extension of the foramen lacerum (as seen in Fig. 7) medial and caudomedial to the petrosal bone, as well as at the (I) basilar part of the occipital bone, (2) occipital condyles flanking the foramen magnum, (3) paracondylar process, (4) petrosal bone, and (5) foramen lacerum (the right foramen is still partly covered by membranous tissue). 
2. Back W, Van der Lugt JJ, Nikkels PGJ, et al. Phenotypic diagnosis of dwarfism in six Friesian horses. Equine Vet J. 2008;40:282-287.

3. Bester RC, Cimprich RE, Evans LH. Hydrocephalus in an 18-month-old colt. J Am Vet Med Assoc. 1976;168:1041-1042.

4. Boerma S, Back W, Sloet van Oldruitenborgh-Oosterbaan MM. The Friesian horse breed: a clinical challenge to the equine veterinarian? Equine Vet Educ. 2012;24:66-71.

5. Bowman RW. Congenital hydrocephalus in 2 foals. Mod Vet Pract. 1980;61:862-864.

6. Budras KD, Sack WO, Röck S, et al. Anatomy of the Horse: An Illustrated Text. 4th ed. Hannover, Germany: Schlütersche $\mathrm{GmbH}$ \& Co. KG Verlag und Drückerei; 2003.

7. Carbery JT. A case of equine hydrocephalus. NZ Vet J. 1979;27:158.

8. Clark FH. Hydrocephalus, a hereditary character in the house mouse. Proc Natl Acad Sci U S A. 1932;18:654-656.

9. Cornillie P, Van den Broeck W, Simoens P. Origin of the infrarenal part of the caudal vena cava in the pig. Anat Histol Embryol. 2008;37:387-393.

10. Cornillie P, Van den Broeck W, Simoens P. Three-dimensional reconstruction of the remodeling of the systemic vasculature in early pig embryos. Microsc Res Tech. 2008;71:105-111.

11. Crowe MW, Swerczek TW. Equine congenital-defects. Am J Vet Res. 1985;46:353-358.

12. Dandy WE. Experimental hydrocephalus. Ann Surg. 1919;70: 129-142.

13. DelBigio MR, Wilson MJ, Enno T. Chronic hydrocephalus in rats and humans: white matter loss and behavior changes. Ann Neurol. 2002;53:337-346.

14. Fernell E, Hagberg G, Hagberg B. Infantile hydrocephalus epidemiology: an indicator of enhanced survival. Arch Dis Child Fetal Neonatal Ed. 1994;70:123-128.

15. Ferris RA, Sonnis J, Webb B, et al. Hydrocephalus in an American Miniature Horse foal: a case report and review. J Equine Vet Sci. 2011;31:611-614.

16. Haverkamp F, Wolfle J, Aretz M, et al. Congenital hydrocephalus internus and aqueduct stenosis: aetiology and implications for genetic counselling. Eur J Pediatr. 1999;158:474-478.

17. Hayward R. Venous hypertension and craniosynostosis. Childs Nerv Syst. 2005;21:880-888.

18. Hochwald GM. Animal models of hydrocephalus: recent developments. Proc Soc Exp Biol Med. 1985;178:1-11.

19. Hodder AD, Ball BA. Theriogenology question of the month: fetal hydrocephalus. J Am Vet Med Assoc. 2008;232:211-213.

20. Johnston I, Teo C. Disorders of CSF hydrodynamics. Childs Nerv Syst. 2000;16:776-799.

21. Jones HC, Bucknall RM. Inherited prenatal hydrocephalus in the H-Tx rat: a morphological study. Neuropathol Appl Neurobiol. 1988;14:263-274.

22. Jubb KVF, Kennedy PC, Palmer N. Nervous system. In: Maxie MG, ed. Pathology of Domestic Animals. 5th ed. Edinburgh, UK: Saunders Elsevier; 2007:304-306.
23. Levine JM, Levine GJ, Hoffman AG, et al. Comparative anatomy of the horse, ox and dog: the brain and associated vessels. Equine Comp Cont Educ Pract Vet. 2008;3:153-164.

24. Marqués FJ, Semrad S, Peek S. Congenital hydrocephalus in a neonatal foal. Equine Comp Cont Educ Pract Vet. 2006;1:105.

25. McGeady TA, Quinn PJ, Fitzpatrick ES, et al. Veterinary Embryology. Oxford, UK: Blackwell; 2006.

26. Moritani T, Aihara T, Oguma E, et al. Magnetic resonance venography of achondroplasia: correlation of venous narrowing at the jugular foramen with hydrocephalus. Clin Imaging. 2006; 30:195-200.

27. Ojala M, Ala-Huikku J. Inheritance of hydrocephalus in horses. Equine Vet J. 1992;24:140-143.

28. Orr N, Back W, Gu J, et al. Genome-wide SNP association based localization of a dwarfism gene in Friesian dwarf horses. Anim Genet. 2010;41:2-7.

29. Petiot MP. Hydrocephalus of the colt. Rec Med Vet Ec Alfort. 1950;126:467-470.

30. Rekate HL. The definition and classification of hydrocephalus: a personal recommendation to stimulate debate. Cerebrospinal Fluid Res. 2008;5:2.

31. Ricketts SW, Barrelet A, Whitwell KE. Equine abortion. Equine Vet Educ. 2003;15:18-21.

32. Rosman NP, Shands KN. Hydrocephalus caused by increased intracranial venous pressure: a clinicopathological study. Ann Neurol. 1978;3:445-450.

33. Sainte-Rose C, LaCombe J, Pierre-Kahn A, et al. Intracranial venous sinus hypertension: cause or consequence of hydrocephalus in infants? J Neurosurg. 1984;60:727-736.

34. Schmidt MJ, Ondreka N, Rummel C, et al. Volume reduction of the jugular foramina in Cavalier King Charles Spaniels with syringomyelia. BMC Vet Res. 2012;8:158.

35. Schrander-Stumpel CT, Vos YJ. From gene to disease; X-linked hydrocephalus and LiCAM. Ned Tijdschr Geneeskd. 2004;148: 1441-1443.

36. Schurr PH, McLaurin RL, Ingraham FD. Experimental studies on the circulation of the cerebrospinal fluid and methods of producing communicating hydrocephalus in the dog. J Neurosurg. 1953; 10:515-525.

37. Sevinga M, Vrijenhoek T, Hesselink JW, et al. Effect of inbreeding on the incidence of retained placenta in Friesian horses. J Anim Sci. 2004;82:982-986.

38. Shotelersuk V, Ittiwut C, Srivuthana S, et al. Distinct craniofacialskeletal-dermatological dysplasia in a patient with W290C mutation in FGFR2. Am J Med Genet. 2002;113:4-8.

39. Steinbok P, Hall J, Flodmark O. Hydrocephalus in achondroplasia: the possible role of intracranial venous hypertension. $J$ Neurosurg. 1989;71:42-48.

40. Velinov M, Slaugenhaupt SA, Stoilov I, et al. The gene for achondroplasia maps to the telomeric region of chromosome $4 \mathrm{p}$. Nat Genet. 1994;6:314-317. 